\title{
Unapproved Drug for Use in Drug Shortage
}

National Cancer Institute

\section{Source}

National Cancer Institute. Unapproved Drug for Use in Drug Shortage. NCI Thesaurus.

Code C101533.

A category of drug products that are not officially approved by the responsible agency.

Drugs in this category have been processed according to standards set forth by the approving agency, and can be considered potential substitutes when the approved medication is unavailable. 